CARDIOVASCULAR EFFECTS OF ADENOSINE IN MAN, Alf

199 Sollevi, Mikael Lagerkranser, Christer Lindqvist, Lars. Irestedt. Dept of Anesthesiology, Karolinska Hospital, Stockholm, Sweden.

The effect of adenosine on central hemodynamics and cerebral blood flow were studied in 30 patients during anesthesia. The studies were approved by the local Ethics committé and performed after informed consent. Hemodynamics were recorded by a SwanGanz catheter and an intraarterial cannula. Cardiac output was determined by the thermodilution technique and cerebral blood flow was quantified by positron-emission-tomography. Adenosine concentrations in plasma was determined by high pressure liquid chromatography. Adenosine infusion $(0.05-0.3 \mathrm{mg} / \mathrm{kg} / \mathrm{min})$ induced a stable hypotension (mean arterial blood pressure, MABP 40-50 $\mathrm{mmHg}$ ), corresponding to 40-50\% reduction of MABP, at an arterial adenosine concentration in the $\mu$ molar range (10-20 fold elevation of basals levals). Dipyridamole pretreatment $(0,3-0,4 \mathrm{mg} / \mathrm{kg}, n=11)$ decreased the dose requirement for adenosine by $50 \%(p<0,01)$. Hypotension was caused by a profound decrease in the systemic vascular resistance $\left(61_{ \pm} 3 \%\right)$, while cardiac output increased by $40_{ \pm}$ $5 \%$. The myocardial filling pressures were not affected by adenosine. The P-R interval of the ECG was significantly prolonged, indicating inhibition of atrioventricular conductance, more prominent after dipyridamole treatment. Whole body oxygen consumption was significantly decreased by $16 \%$, without elevation of lactate levels. Adenosine induced a general increase in cerebral blood flow, during normoventilation $(n=3)$, and in cortical areas the flow was increased 2-3 fold.

Adenosine is a powerful dilator of the resistance vessels in man.

\section{ACUTE ATTACK OF GOUT TRIGGERED BY} Maria L. Sorgi, A. Giacomello, A. Zoppini

Acute attack of gout triggered by allopurinol has been studied by a retrospective analysis of 134 patients with gout treated with this drug. The results suggest that:

a) mobilization of tophaceous deposits in the joints play an important part in the pathogenesis of the acute attack of gout triggered by allopurinol.

b) acute gouty attacks after the initiation of allopu rinol therapy are more frequent and occur earlier in patients not receiving than in those receiving prophylactic colchicine or indomethacin.

The acute attack of gout triggered by allopurinol is proposed as an "ex ingravescentibus" diagnostic criteria when the patient is seen in an intercritical period.
ADENINE NUCLEOTIDE DEGRADATION IN THE HUMAN

200 MYOCARDIUM DURING CARDIOPLEGIA: Alf Sollevi, Walter Schmidt, Eva Jansson, Wollmer Bomfim Lennart Kaijser. Department of Pharmacology, Karolinska Institutet, and Department of Clinical Physiology, Karolinska Hospital, Stockholm, Sweden.

Myocardial ischemia is associated with adenine nucleotide degradation and accumulation of nucleosides and bases. Data regarding adenine nucleotide degradation in ischemic human myocardium is limited. The adenine nucleotides, IMP, adenosine, inosine, hypoxanthine and uric acid were determined by high pressure liquid chromatography, in biopsies (1.5-4 mg) from human left ventricular myocardium during cardioplegia (at $10-15^{\circ} \mathrm{C}$ ) in six patients (aged 35-64 year) subjected to aortic valve replacement surgery. The study was performed after informed consent and approval from the Ethics Commité. The first biopsy was collected after induction of cardioplegia and the second 45-60 min later. The myocardium was perfused with diluted cold blood $25-30 \mathrm{ml} / \mathrm{min}$ (with $20 \mathrm{mM}$ potassium). The ATP concentration was $12.64+1.96 \mathrm{mmoles} / \mathrm{kg}$ dry muscle (d.m.) after induction and decreasēd by $37+5 \%(p<0.01)$ AMP ranged between 2 and 3 mmoles $/ \mathrm{kg}$ d.m., while IMP was consistently low, $(0.11+0.01$ mmoles $/ \mathrm{kg} \mathrm{d} . \mathrm{m}$.$) . The adenosine concentra-$ tion was high, $(0.26+0.04 \mathrm{mmol} / \mathrm{kg} \mathrm{d.m.})$, and inosine increased from 0.82 to 2.66 mmöles $/ \mathrm{kg}(p<0.01)$. Approximately 3 mmoles $/ \mathrm{kg}$ d.m. of purine material was probably washed out of tissue during the perfusion. In conclusion, cardioplegia is associated with severe ischemia and the major route fo AMP degradation is probably through adenosine.

RELEASE OF ADENOSINE FROM THE ISCHEMIC HUMAN HEART. Alf Sollevi, Lennart Kai jser, Bertil B. Fredholm. Department of Pharmacology, Karolinska Institutet Stockholm, Sweden.

Adenosine is released from the mammalian heart during ischemia. Yet, it has proven difficult to demonstrate adenosine release following coronary sinus (cs) catheterization in pacinginduced angina. In this study, dipyridamole (Dip, an inhibitor of adenosine uptake) was used to facilitate detection of adenosine release during myocardial ischemia. Methods: Seven patients with ischemic heart disease (IHD) and five healthy volunteers were studied by arterial (a) and cs catheterization, after informed consent and approval from the Ethics Commité. Atrial pacing to angina or heart rate (HR) 150 (in volunteers) were performed before and during continuous dipyridamole infusion $(5 \mu \mathrm{g} / \mathrm{kg} / \mathrm{min}$ ). Cs blood flow (CSBF, thermodilution technique), a-cs differences for adenosine and hypoxanthine (by high pressure liquid chromatography), lactate and $0_{2}$ were measured before, during and after pacing. Results: Pacing increased CSBF ( $53 \%$ in IHD and $60 \%$ in volunteers) and $\mathrm{O}_{2}$ uptake. IHD released lactate and hypoxanthine but not adenosine. Dipyridamole (1-1.5 $\mathrm{MM}$ in plasma) did not affect $H R, B P$ or $0_{2}$ uptake but increased resting CSBF (18\%) in all subjects. During pacing, $\operatorname{CSBF}$ was enhanced in volunteers but not in IHD, in comparison to control pace. The a-cs difference for adenosine $(-0.17+0.06 \mu \mathrm{M}, p<0.05)$ was different from prepacing $(p<0.01)$ in IHD. Hypoxanthine release tended to be even higher than during and after the control pacing, while the a-cs difference for adenosine and hypoxanthine were unaffected in volunteers. In conclusion, angina causes release of adenosine.
INTRACELLULAR PURINE AND PYRIMIDINE NUCLEOTIDE

203 POOLS OF HUMAN T AND B . LYMPHOCYTES OF DIFFERENT MATURATION STAGES. Leo J.M: Spaapen, John G.M. Scharenberg, Ben J.M. Zegers, Ger T. Rijkers, Marinus Duran, Immunology, Utrecht, The Netherlands.

It is we11 established that the activities of various enzymes of the purine and pyrimidine metabolic pathways vary between $T$ and $B$ lymphocytes and with the maturational stage of the lymphoid cells of both lineages. In the present study we investigated by HPLC analysis whether these differences are reflected in differences in intracellular purine and pyrimidine nucleotide pools. The intracellular nucleotide pools, expressed as the ratio of total purine nucleotides over total pyrimidine nucleotides do increase with the maturational development of $T$ and B lymphocytes: thymocytes < cord blood T cells < adult peripheral $\mathrm{T}$ cells; cord blood $\mathrm{B}$ cells < adult peripheral $\mathrm{B}$ cells. Moreover it was found that this ratio decreased upon mitogenic stimulation of peripheral blood $\mathrm{T}$ cells, whereas it increased upon mitogenic stimulation of $B$ cells. These data should be useful as reference levels e.g. in the interpretation of purine/ pyrimidine nucleotide pool ratio's of leukaemic cells representing different stages of lymphocyte development.
204 STEADY-STATE KINETICS OF THE REACriON CATALYZED BY GMP REDUCTASE.

A. Spadaro, A. Giacomello, C. Salerno Institutes of Rheumatology and Biological Chemistry, University of Rome, and C.N.R. Centre for Melocular Biology, Rome, Italy.

GMP reductase (EC 1.6 .6 .8 ) has been purified from human erythrocytes. The steady-state kinetics of the reaction catalyzed by GMP reductase are consistent with a model in which substrates bind the enzyme in an ordered sequence, first GMP and then NADPH. NADP is released from the enzyme-substrate complex by a Theorell-chance mechanism. Ammonia and IMP are then sequentially liberated in an ordered fashion. Deadend complexes between the enzyme and ammonia have been observed. GTP $(10-200 \mathrm{uM})$ increases the apparent second-order rate constant for GMP binding and thus decreases the inhibition constant of this substrate. Neither Vmax nor $\mathrm{Km}$ for NADPH are affected by GTP up to $200 \mathrm{uM}$. 